\title{
Where do Chinese scientists publish their research in environmental science and technology?
}

\author{
Yong-Guan Zhu ${ }^{\mathrm{a}, *}$, Patrick O'connor ${ }^{\mathrm{b}}$, Jing-Hua Cao ${ }^{\mathrm{c}}$ \\ ${ }^{a}$ Research Center for Eco-environmental Sciences, Chinese Academy of Sciences, 18 Shuangqing Road, Beijing 100085, China \\ ${ }^{\mathrm{b}}$ School of Earth and Environmental Sciences, The University of Adelaide, SA 5005, Australia \\ ${ }^{c}$ Bureau of International Cooperation, Chinese Academy of Sciences, 52 Sanlihe Road, Beijing 100045, China
}

Received 19 October 2006; received in revised form 20 October 2006; accepted 21 October 2006

Keywords: China; Publication

In the last 10 years there has been a sharp increase in international publications coming out of China. By using "China" in the address category as the criteria for searching ISI database, it is found that the number of papers published, with at least one author from an institution in China, in Science citation index (SCI) journals increased from 828 in 1990 to 73,890 in 2005 , increasing nearly 100 times over the period of 15 years. This increase is perhaps the most striking phenomena in the history of scientific publication and indicates that China is an emerging force in scientific research, including research in environmental science and technology.

To evaluate the trend of international publications in environmental science and technology from China, we examined results from typical journals published outside of China (listed in Table 1). The number of papers on environmental science and technology published in international journals follows the same trend as that for all publications over the same period. The number of papers published in these journals increased exponentially from two papers in 1990 to 493 papers in 2005 (Fig. 1). Among these journals, Chemosphere published the largest number of papers from Chinese authors, reaching nearly 700 in total over the last 10 years. This is followed by Bulletin of Environmental Contamination and Toxicology (BECT) and Environmental Science and Technology with more than 200 papers in each journal (Table 1). The Journal of Environmental

\footnotetext{
* Corresponding author.

E-mail address: ygzhu@mail.rcees.ac.cn (Y.-G. Zhu).
}

Science and Health-A, The Science of the Total Environment, Water, Air and Soil Pollution, Environmental Pollution, and Journal of Hazardous Materials published between 90 and 200 papers each over the same period.

In terms of the number of papers, it has now reached the stage where scientists from China are publishing papers in international journals in volumes comparable to other major countries publishing in the field of environmental science and technology. For example, from 1996 to 2006, there were 174 papers authored by Chinese scientists in the journal Environmental Pollution, while in the same period USA scientists published 819 papers and UK scientists published 548 papers. The number of papers from China was similar to that from Japan and France and comparable with the number from Germany (Fig. 2). However, it is expected that there will be a continuing increase in papers published in international journals, since currently China has an R\&D workforce totaling 32 million. Current publishing rates for Chinese scientists may also be expected to grow as a consequence of the relatively recent introduction of major policy initiatives promoting scientific research and internationalization at all levels. The National Natural Science Foundation of China (NSFC), the major powerhouse of basic research in China, has witnessed a steady increase in funding in the last 10 years, with current annual support of around RMB 3 billion, and the likelihood of another doubling in the next 5 years. To boost basic research in China, the Ministry of Science and Technology (MOST) has initiated a major program entitled the "National Key Basic Research Program" (973 program), and an increasing number of environmental 
Table 1

Number of publications by Chinese scientists in major environmental science journals from 1996 to 2005

\begin{tabular}{|c|c|c|}
\hline Journal title & Publisher & $\begin{array}{l}\text { Number of } \\
\text { publications }\end{array}$ \\
\hline Chemosphere & Elsevier & 566 \\
\hline $\begin{array}{l}\text { Bulletin of Environmental } \\
\text { Contamination } \\
\text { and Toxicology }\end{array}$ & Springer & 292 \\
\hline $\begin{array}{l}\text { Environmental } \\
\text { Science \& Technology }\end{array}$ & ACS Publications & 226 \\
\hline $\begin{array}{l}\text { Journal of Environmental } \\
\text { Science and Health, } \\
\text { Part A Environmental } \\
\text { Science and Engineering }\end{array}$ & Taylor \& Francis & 184 \\
\hline Water, Air and Soil Pollution & Springer & 142 \\
\hline Science of the Total Environment & Elsevier & 138 \\
\hline Environmental Pollution & Elsevier & 121 \\
\hline Journal of Hazardous Materials & Elsevier & 91 \\
\hline Environment International & Elsevier & 87 \\
\hline $\begin{array}{l}\text { Environmental Toxicology } \\
\text { and Chemistry }\end{array}$ & $\begin{array}{l}\text { SETAC and Alliance } \\
\text { Communications Group }\end{array}$ & 54 \\
\hline Journal of Environmental Quality & ASA, CSSA and SSSA & 41 \\
\hline $\begin{array}{l}\text { Journal of Environmental } \\
\text { Science and Health, } \\
\text { Part B Pesticides, } \\
\text { Food Contaminants } \\
\text { and Agricultural Wastes }\end{array}$ & Taylor \& Francis & 20 \\
\hline $\begin{array}{l}\text { Environmental Science } \\
\text { and Pollution Research }\end{array}$ & ECOMED Publishers & 18 \\
\hline
\end{tabular}

science and technology projects have been supported through this program. The Chinese Academy of Sciences, through its Knowledge Innovation Program (KIP) is also supporting an expanded basic and strategic research.

Within China, environmental science and technology research programs are carried out nationwide, however there are several key centers producing the bulk of international papers. These centers include Beijing, Nanjing, Hangzhou, Guanzghou, Shanghai, Wuhan, Tianjin and Shenyang. Papers in the journal Environmental Science and Technology from these eight cities account for $73 \%$ of the total papers published

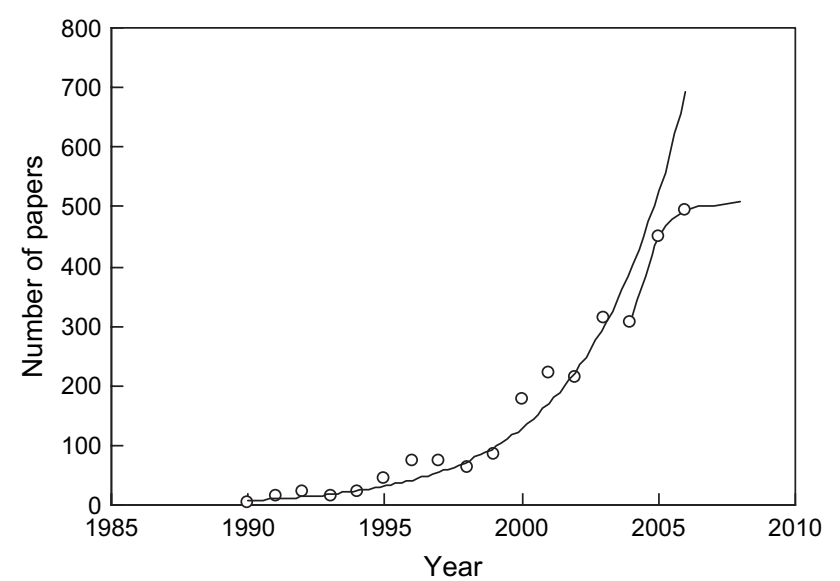

Fig. 1. The increase in number of papers authored by Chinese scientists published in the international journals listed in Table 1.

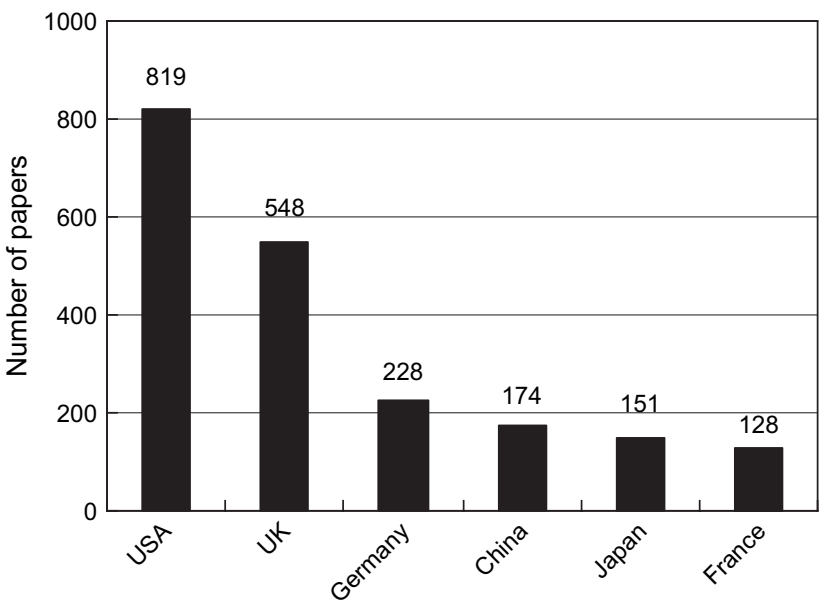

Fig. 2. Comparison of papers published in the journal Environmental Pollution from different countries within the period of last 10 years.

from China in this journal over the last 10 years (Fig. 3). Similarly, papers from these cities account for $70 \%$ of papers from China in the journal Environmental Pollution (Fig. 3). Amongst these eight cities, Beijing contributes the highest number of papers in these two journals, followed by Nanjing, Hangzhou and Guangzhou. These figures probably reflect the number of institutes of the Chinese Academy of Sciences and key universities which undertake work in the field of environmental science and technology in these cities.

The significant and continuous efforts of the Chinese government to fund quality scientific research, and the determination to promote innovation-oriented development of the nation, indicate that the drive for international scientific publication from China will remain strong. The sharp increase in international scientific publication also reflects the enthusiasm and dedication of Chinese scientists, and their eagerness to participate fully in the dialogue of international science and technology. Given the contrast in culture and language of

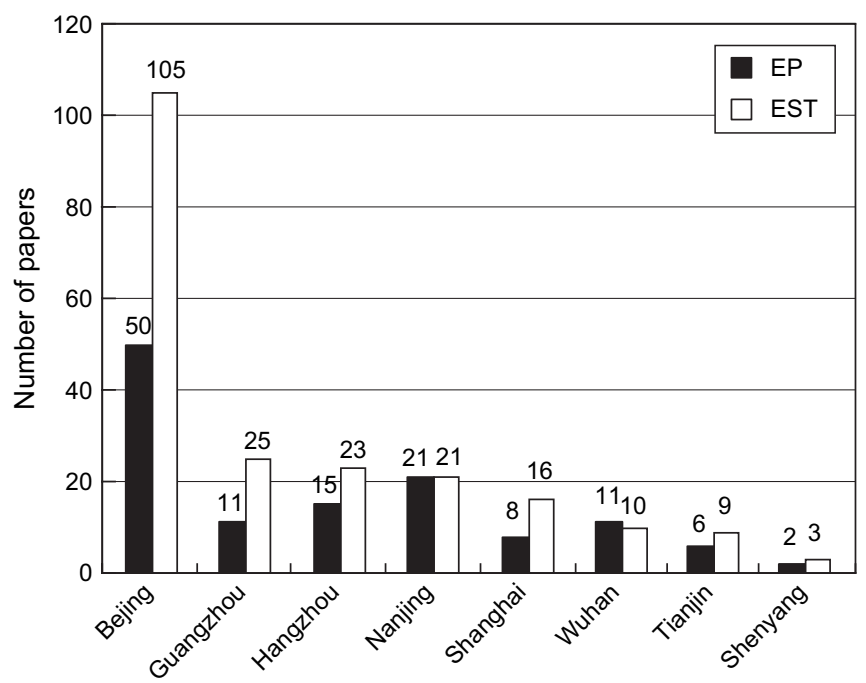

Fig. 3. Geographical distribution of paper contributions from eight cities within China in last 10 years. EP, Environmental Pollution; EST, Environmental Science and Technology. 
publication, in the largely English-language dominated world of scientific communication, and the daunting task of solving domestic environmental problems in the process of rapid economic expansion of the nation, the willingness of Chinese scientists to take the challenge of writing and international peer review should be appreciated. Increasing recognition of the importance of research undertaken in China and of the increased capacity of Chinese scientists to communicate this research to an international audience is demonstrated by the increasing prominence of Chinese authors in the international literature. Science journals are also recognizing the strong growth in this sector in China, and the journal Environmental Pollution has recently organized a special issue with the theme of environmental science and technology in China. What can now be measured as the impact of Chinese scientists on science publishing will increasingly be measured as the impact of Chinese scientists on scientific thinking and research and development. 